\title{
An analysis of possible assessment of hazards to ship shaft line, resulting from impulse load
}

\author{
Andrzej Grządziela \\ Polish Naval University
}

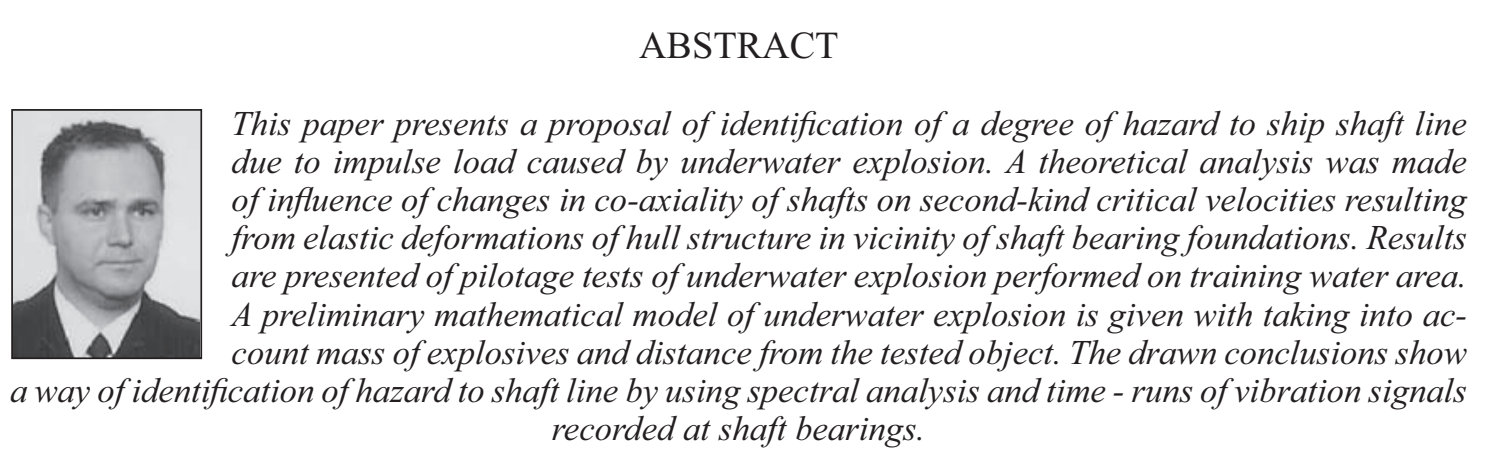

Keywords : ship shaft lines, technical diagnostics, modelling, vibrations, underwater explosion

\section{INTRODUCTION}

Ship propulsion systems are subjected to specific sea loads due to waving and dynamical impacts associated with mission of a given ship. Sea waving can be sufficiently exactly modeled by means of statistical methods. Much more problems arise from modelling impacts due to underwater explosion. In operation of contemporary technical objects including naval ships greater and greater attention is paid to such notions as : time of serviceability, repair time, maintenance and diagnosing costs [1]. Diagnosing process has become now a standard procedure performed during every technical maintenance. Out of the above mentioned, the notions of time of serviceability and maintenance costs seem to be crucial for the diagnosing process of ship power plant. Knowledge of a character of impulse loading which affects ship shaft line, can make it possible to identify potential failures by means of on-line vibration measuring systems. This way elimination of costly and time-consuming overhauls on dock leads to lowering operational costs and increasing ship fighting merits.

\section{ANALYSIS OF FORCES ACTING ON SHAFT-LINE BEARINGS}

Ship shaft lines are subjected to loads in the form of forces and moments which generate bending, torsional and axial vibrations. In most cases strength calculations of driving shafts are carried out by using a static method as required by majority of ship classification institutions. Moreover they require calculations of torsional vibrations which have to comply with permissible values, to be performed. Calculation procedures of ship shaft lines generally amount to determination of reduced stresses and safety factor related to tensile yield strength of material - Fig.1.

The above mentioned methods do not model real conditions of shaft-line operation, which is confirmed by the character of ship hull response, i.e. its deformations under dynamic loads. Much more reliable would be to relate results of the calculations to fatigue strength of material instead of its yield strength [5].

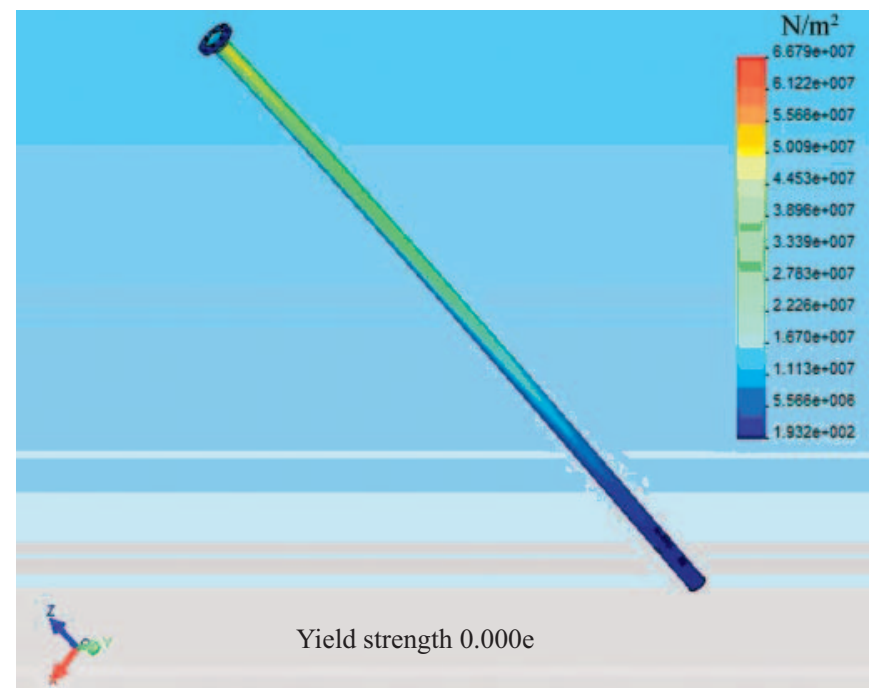

Fig.1. Simulated static bending stresses in propeller shaft due to weight of propeller. 
In static calculation procedures no analysis of dynamic excitations, except torsional vibrations, is taken into consideration. In certain circumstances the adoption of static load criterion may be disastrous especially in the case of resonance between natural vibration frequencies and those of external forces due to dynamic impacts. To analyze the dynamic interaction a simplified model of shaft line is presented below, Fig. 2 .
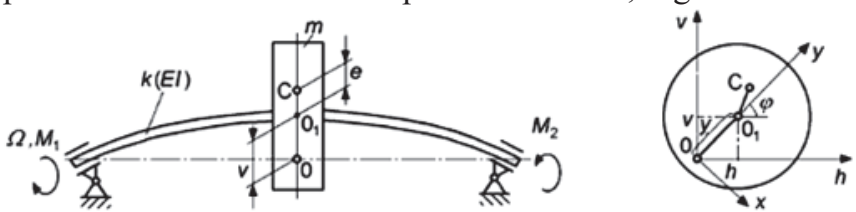

Fig. 2. A simplified shaft-line model for critical speed calculation [4]

Let us note : $\mathrm{M}_{1}$ - torque, $\mathrm{M}_{2}$ - anti-torque. The system can be represented by the following set of equations :

$$
\begin{gathered}
\mathrm{m} \ddot{\mathrm{h}}+\mathrm{kh}=\mathrm{me}\left(\ddot{\varphi} \sin \varphi+\dot{\varphi}^{2} \cos \varphi\right) \\
\mathrm{m} \ddot{\mathrm{v}}+\mathrm{kh}=\mathrm{me}\left(-\ddot{\varphi} \cos \varphi+\dot{\varphi}^{2} \sin \varphi\right) \\
\left(\mathrm{J}+\mathrm{me}^{2}\right) \ddot{\varphi}=\operatorname{me}(\ddot{\mathrm{h}} \sin \varphi-\ddot{\mathrm{v}} \cos \varphi)+\mathrm{M}_{1}-\mathrm{M}_{2}
\end{gathered}
$$

The presented form of the equations is non-linear. Considering the third of the equations (1) one can observe that the variables $h, v$ and $\varphi$ are mutually coupled. It means that any bending vibration would disturb rotational motion of the shaft. The third of the equations (1) can be written also in the equivalent form as follows :

$$
\mathrm{J} \ddot{\varphi}=\mathrm{ke}(\mathrm{v} \cos \varphi-\mathrm{h} \sin \varphi)+\mathrm{M}_{1}-\mathrm{M}_{2}
$$

To obtain the shaft angular speed $\Omega=\dot{\mathrm{e}}$ constant to use time-variable torque is necessary :

$$
\mathrm{M}=\mathrm{M}_{1}-\mathrm{M}_{2}=\mathrm{ke}(\mathrm{h} \sin \varphi-\mathrm{v} \cos \varphi)
$$

Theoretical analysis indicates that shaft bending deformation continuously accumulates a part of shaft torque. However the quantity of torque non-uniformity is rather low since shaftline eccentricity is low; it results from manufacturing tolerance, non-homogeneity of material, propeller weight and permissible assembling clearances of bearing foundations. The condition makes it possible to predict that run-out of propeller shaft may also happen at other rotational speeds than the critical $1^{\text {st }}$ kind speed calculated during design process. Taking into account the torque variability one can express Eq. (1) as follows:

$$
\begin{gathered}
\ddot{\mathrm{h}}+\omega_{0}^{2} \mathrm{~h}=\mathrm{e} \Omega^{2} \cos \varphi \\
\ddot{\mathrm{v}}+\omega_{0}^{2} \mathrm{~h}=\mathrm{e} \Omega^{2} \sin \varphi \\
\ddot{\varphi}=\frac{1}{\mathrm{~J}} \mathrm{M}(\mathrm{t})
\end{gathered}
$$

On assumption that the average angular speed of propeller shaft equals $\Omega$, the angle $\varphi$ will change with time according to the equation :

$$
\varphi=\Omega \mathrm{t}+\varphi_{0}
$$

and the torque $\mathrm{M}(\mathrm{t})$ can be represented as follows :

$$
\mathrm{M}(\mathrm{t})=\mathrm{M}_{1}-\mathrm{M}_{2}=\mathrm{a}_{\beta} \cdot \cos \left(\beta \Omega \mathrm{t}+\eta_{\beta}\right)
$$

For ship propulsion system the torque pulsation expressed by means of Fourier series is much more complex. It additionally contains components resulting from number of propeller blades, kinematical features of reduction gear as well as disturbances from main engine and neighbouring devices. In general case occurrence of only one harmonic does not change reasoning logic. After solving the third of Eqs.(4) and substituting Eq.(5) to the obtained expression one obtains the following:

$$
\varphi=\frac{\mathrm{a}_{\beta}}{\beta^{2} \Omega^{2} \mathrm{~J}} \cos (\Omega \mathrm{t}+\eta)+\mathrm{C}_{1}+\mathrm{C}_{2}
$$

If $\Omega=$ const then $C_{1}=0$. Similarly: $C_{2}=0$ as $C_{2}$ determines displacement of the vibration centre axis but does not change character of shaft motion, hence to neglect both the integrating constants is possible. Assuming additionally that generated vibrations are of low energy as compared with the power transmitted by the shaft, i.e. $\cos \eta=1$ and $\sin \eta \approx \eta$, and using trigonometric transformations one can obtain the following [4]:

$$
\begin{gathered}
\ddot{\mathrm{h}}+\omega_{0}^{2} \mathrm{~h}=\mathrm{e} \Omega^{2} \cos \varphi+ \\
+\frac{\mathrm{e} \cdot \mathrm{a}_{\beta}}{2 \beta^{2} \mathrm{~J}}\left\{\sin \left[(\beta+1) \Omega \mathrm{t}+\eta_{\beta}\right]-\sin \left[(\beta-1) \Omega \mathrm{t}+\eta_{\beta}\right]\right\} \\
\ddot{\mathrm{v}}+\omega_{0}^{2} \mathrm{v}=\mathrm{e} \Omega^{2} \cos \varphi+ \\
-\frac{\mathrm{e} \cdot \mathrm{a}_{\beta}}{2 \beta^{2} \mathrm{~J}}\left\{\cos \left[(\beta+1) \Omega \mathrm{t}+\eta_{\beta}\right]+\cos \left[(\beta-1) \Omega \mathrm{t}+\eta_{\beta}\right]\right\}
\end{gathered}
$$

From Eqs. (8) one obtains three harmonic excitations : $\Omega$, $(\beta+1) \Omega$ and $(\beta-1) \Omega$. Hence assuming that the torque pulsation occurs with the frequency $\beta \cdot \Omega$ one obtains three cases of resonance for one degree of freedom of propeller shaft:

$$
\begin{gathered}
\Omega_{1 \mathrm{KR}}=\omega_{0} \\
\Omega_{2 \mathrm{KR}}=\frac{1}{\beta-1} \omega_{0} \\
\Omega_{3 \mathrm{KR}}=\frac{1}{\beta+1} \omega_{0}
\end{gathered}
$$

where : $\Omega_{2 \mathrm{KR}}, \Omega_{3 \mathrm{KR}}$ - critical rotational speeds of $2^{\text {nd }}$ kind. The above given considerations deal only with one torque pulsation harmonic. In practice, at a greater number of excitations including instantaneous elastic deformations due to impulse loading, one should expect a series of critical speeds of $2^{\text {nd }}$ kind whose influence will be reduced by damping due to water, stuffing-box and bearing supports [6].

For long shaft lines of ships the influence of gravity forces on critical speeds should be taken into consideration [7]. According to Eq. (10) the generated vibrations will be then performed respective to static deflection axis of the shaft.

$$
\begin{aligned}
\mathrm{m} \ddot{\mathrm{h}}+\mathrm{kh} & =\mathrm{me} \Omega^{2} \cos \varphi \\
\mathrm{m} \ddot{\mathrm{v}}+\mathrm{kv} & =\mathrm{me} \Omega^{2} \sin \varphi \\
\ddot{\varphi} & =0
\end{aligned}
$$

Hence the equations obtain the following form:

$$
\begin{gathered}
\ddot{\mathrm{h}}+\omega_{0}^{2} \mathrm{~h}=\mathrm{e} \cdot \Omega^{2} \cos \varphi \\
\ddot{\mathrm{v}}+\omega_{0}^{2} \mathrm{v}=\mathrm{e} \cdot \Omega^{2} \sin \varphi-\mathrm{mg} \\
\mathrm{J} \ddot{\varphi}=-\mathrm{mge} \cos \varphi
\end{gathered}
$$

Since in the third equation of the set (9), i.e. that for $\Omega_{3 \mathrm{KR}}$, appears the exciting torque of the frequency/angular speed ratio $\beta=1$ it means that one has to do with the critical state of $2^{\text {nd }}$ kind for $\beta=1$, namely :

$$
\Omega_{\mathrm{KR}(2)}=\frac{1}{2} \omega_{0}
$$

Occurrence of such kind vibrations is conditioned by non-zero value of $e$, which - in the case of ship shaft line - appear just after dislocation of a weight along ship, a change of ship displacement or even due to sunshine operation on one of ship 
sides. A similar situation will happen when $e$ varies due to dynamic excitations resulting from e.g. sea waving or explosion. In this case the critical speed will vary depending on instantaneous value of $e$ and damping.

Theoretical analysis of operational conditions of intermediate and propeller shafts indicates that static and dynamic loads appear. In a more detailed analysis of dynamic excitations of all kinds the following factors should be additionally taken into consideration :

> disturbances coming from ship propeller (torsional, bending and compressive stresses);

$>$ disturbances from propulsion engine (torsional and compressive stresses);

$>$ disturbances from reduction gear (torsional stresses);

$>$ disturbances from other sources characteristic for a given propulsion system or ship mission.

\section{THEORETICAL BACKGROUND OF UNDERWATER EXPLOSION}

Information on potential hazard resulting from underwater explosion is crucial not only for ship's commander during warfare but also for ship structure designers. Knowledge of loads determined during simulative explosions is helpful in dimensioning ship's hull scantlings [3]. Another issue is possible quantification of explosion energy as well as current potential hazard to whole ship and its moving system.

From the point of view of shock wave impact on shaft line, underwater and over-water explosions should be considered in two situations :

$\rightarrow$ when shock wave (or its component) impacts screw propeller axially

$\rightarrow$ when shock wave (or its component) impacts screw propeller perpendicularly to its rotation axis.

The axial shock-wave component affects thrust bearing and due to its stepwise character it may completely damage sliding thrust bearing. Rolling thrust bearings are more resistant to stepwise loading hence they are commonly used on naval ships [3]. The shock wave component perpendicular to shaft rotation axis is much more endangering.

Shock wave can cause: damage of stern tube, brittle cracks in bearing covers and tracks, plastic displacement of shaft supporting elements including transmission gear and main engine, and even permanent deformation of propeller shaft. For that reason contemporary naval ships are tested regarding their shock strength - irrespective of their mission - already during sea trials, Fig.3.

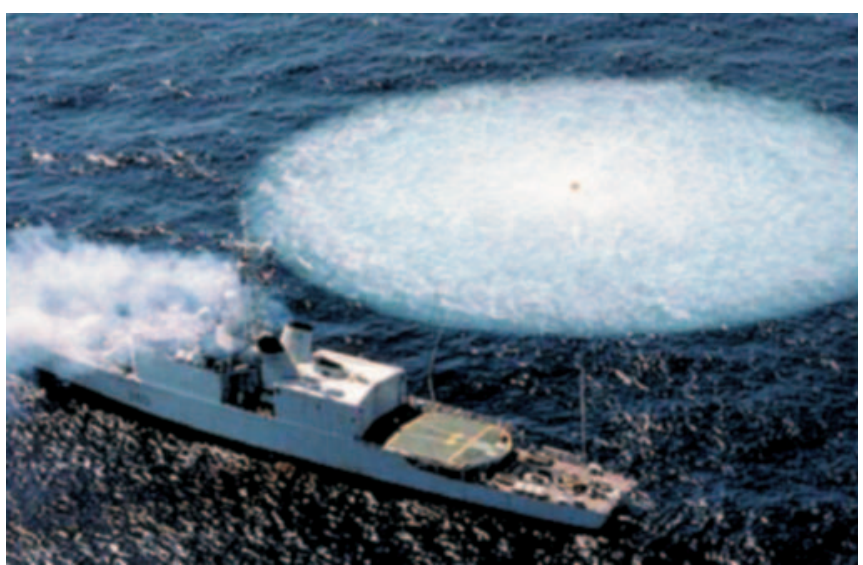

Fig. 3. Experimental tests of shock strength of frigates against underwater explosion
The problem of influence of sea mine explosion on hull structure is complex and belongs to more difficult issues of ship dynamics. Underwater explosion is meant as a violent upset of balance of a given system due to detonation of explosives in water environment. The process is accompanied with emission of large quantity of energy within a short time, fast running chemical and physical reactions, emission of heat and gas products. The influence of underwater explosion does not constitute a single impulse but a few ( 2 to 4 ) large energy pulsations of gas bubbles $[2,8,9]$. The pulsation process is repeated several times till the instant when the gas bubble surfaces. Hence the number of pulsations depends a.o. on immersion depth of the explosive charge. The character of changes of pressure values in a motionless point of the considered area is shown in Fig.4.

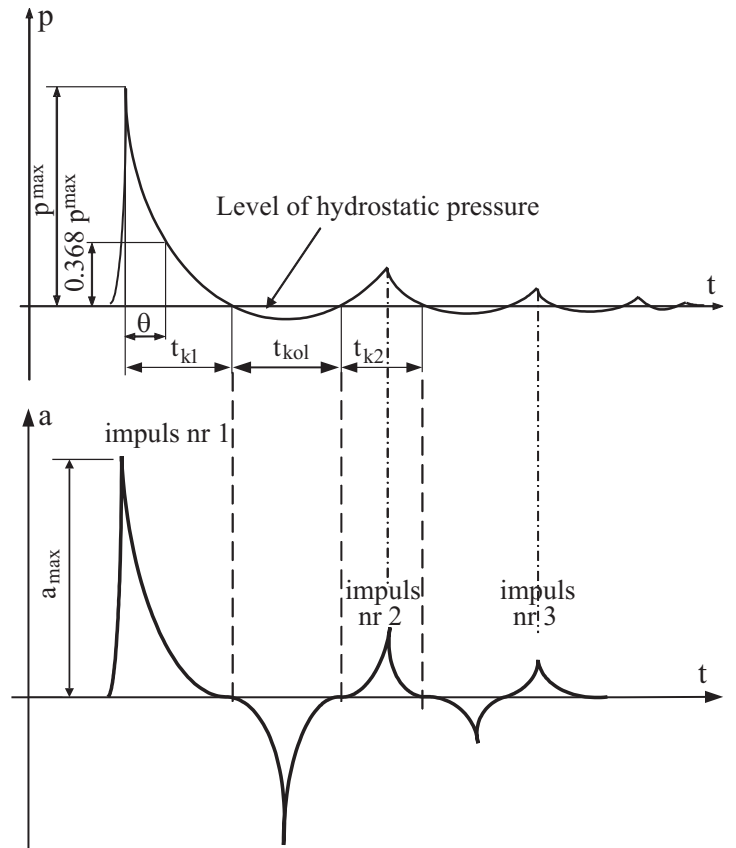

Fig. 4. Run of changes of shock wave pressure and ship hull acceleration measured on hull surface during underwater explosion

In the subject-matter literature can be found many formulae for determining maximum pressure value, based on results of experiments, however data on a character of pulsation and its impact on ship structures are lacking.

\section{EXPERIMENTAL TESTS}

To identify underwater explosion parameters a pilotage test was performed with the use of the explosive charge having the mass $m=37.5 \mathrm{~kg}$. The schematic diagram of the experiment is shown in Fig. 6. During the test were measured vibration accelerations of casings of intermediate and thrust bearings in the thrust direction and that perpendicular to shaft rotation axis. The ship course angle relative to the explosion epicentre was $45^{\circ}$ and the shaft line rotated with the speed $n_{L W}=500$ rpm. Ship's distance from the mine and its immersion depth was determined by using a hydro-location station and ROV underwater vehicle. The vibration gauges were fixed over the reduction gear bearing (p. 1) as well as on the intermediate shaft bearing (p. 2) as shown in Fig.5. The measurement directions ( $\mathrm{X}$ and $\mathrm{Z}$ axes) are presented in Fig.6.

The performed test was aimed at achieving information dealing with :

$\Rightarrow$ character of shock wave impact on shaft-line bearings, in the form of recorded vibration parameters

$\Rightarrow$ assessment of time-run of vibration accelerations with taking into account dynamic features of the signals in set measurement points 
$\Rightarrow$ assessment of possible identification of influence of pulsation of successive gas bubbles during the time-run of vibration accelerations

$\Rightarrow$ identification of features of the signals by means of spectral analysis.

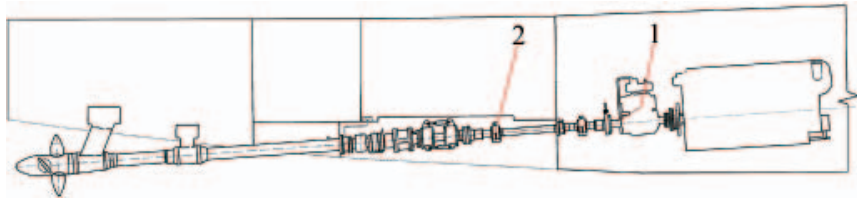

Fig. 5. Schematic diagram of the propulsion system of the ship in question. 1 - measurement point of 3-dimensional vibration at reduction gear;

$$
2 \text { - measurement point of 3-dimensional vibration }
$$
at shaft-line intermadiate bearing

Since the mass of the explosive charge was small, to reliably identify the effect of only first and second pulsation was possible during the test. The time lag of the recorded signals was the same in all measurement points, as shown in Fig.7 and 8.

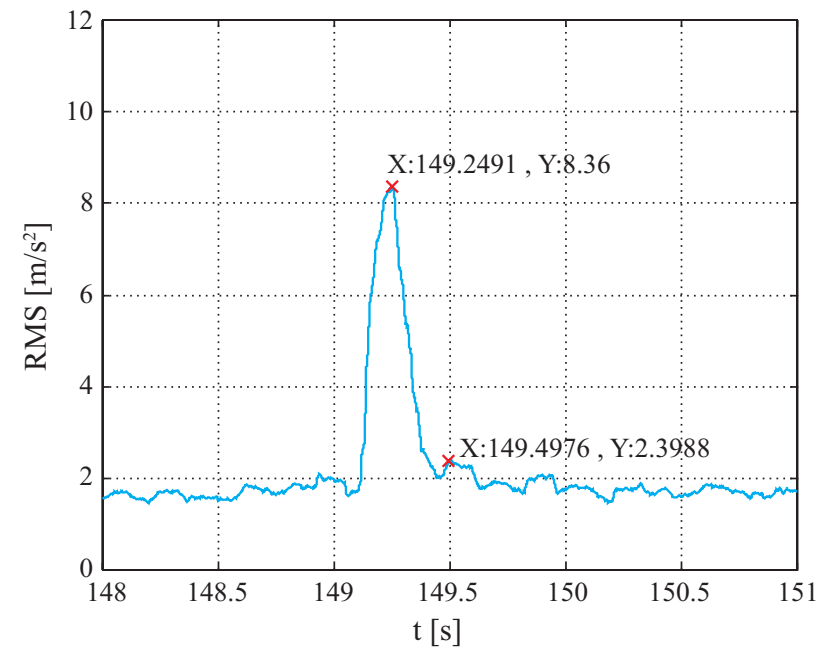

Explosion, Port side(LB), Thrust bearing, $X$ axis

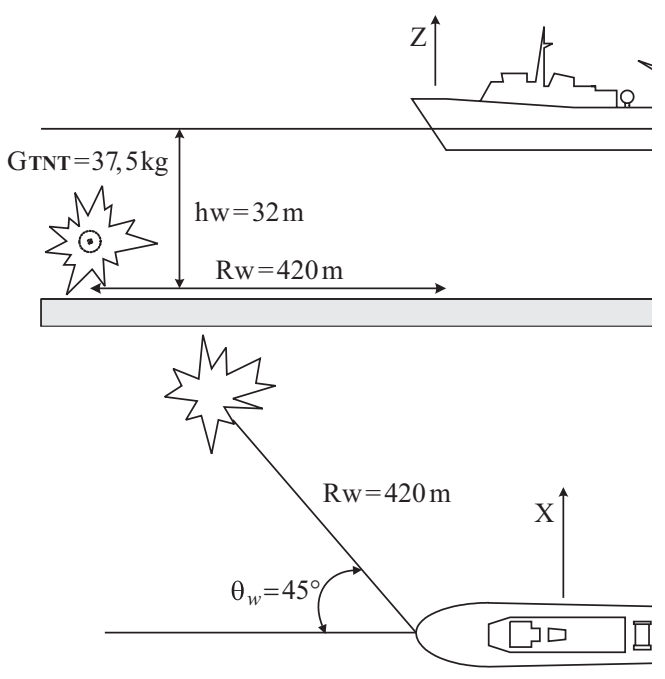

Fig. 6. Schematic diagram of the performed experimental test.

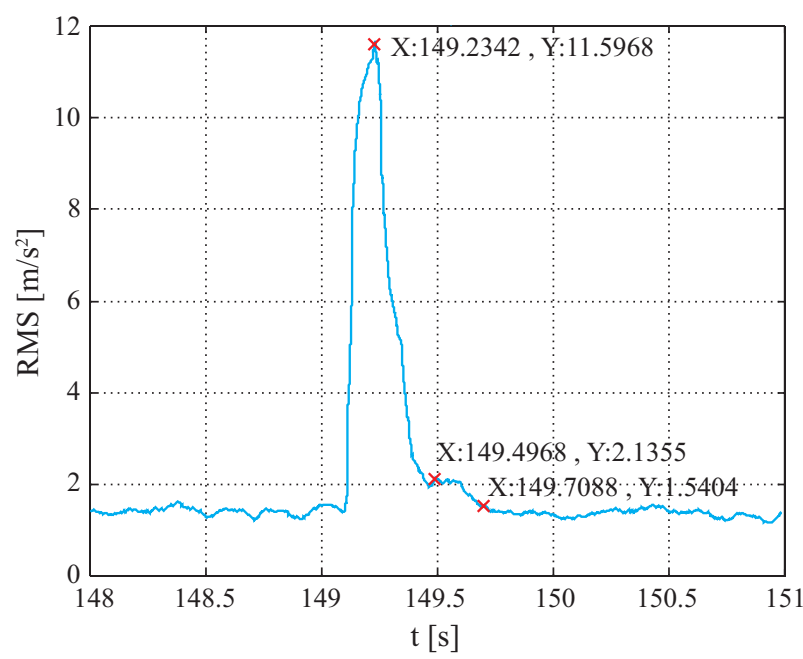

Explosion, Starboard (PB), Intermediate bearing, $Z$ axis

Fig. 7. Rms values of vibration accelerations recorded on port side (LB) and starboard (PB) intermediate bearings and thrust bearings
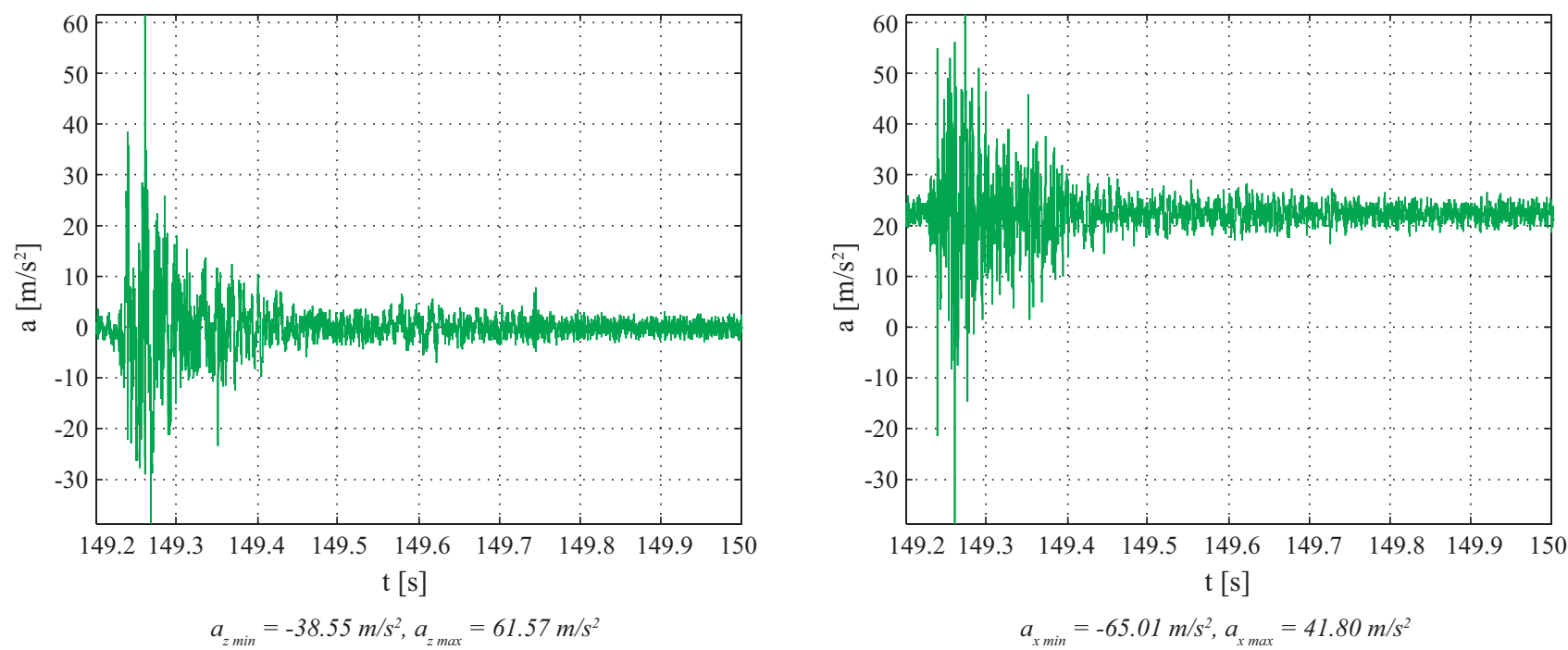

Fig. 8. Time-run of vibration accelerations in two measurement points .

The most important information was the assessment of the ratios of maximum and minimum values of vibration accelerations measured before, during and after underwater explosion.

The performed analysis concerned all the measurement points, Tab.1. 
Tab. 1. Ratios of vibration accelerations in the measurement points K1 through K8

\begin{tabular}{|c|c|c|c|c|}
\hline \multicolumn{5}{|c|}{ Indices 1 min before explosion } \\
\hline Measurement points: & K2 & K1 & K6 & $\mathrm{K} 5$ \\
\hline $\mathrm{a}_{\max } / \mathrm{a}_{\min }$ & 1.21 & 0.88 & 0.8 & 0.82 \\
\hline Measurement points: & K4 & K3 & K8 & K7 \\
\hline $\mathrm{a}_{\max } / \mathrm{a}_{\min }$ & 1.24 & 0.9 & 1.02 & 1 \\
\hline \multicolumn{5}{|c|}{ Indices during explosion } \\
\hline Measurement points: & K2 & K1 & K6 & K5 \\
\hline $\mathrm{a}_{\max } / \mathrm{a}_{\min }$ & 13.02 & 9.23 & 11.90 & 10.02 \\
\hline Measurement points: & K4 & K3 & K8 & K7 \\
\hline $\mathrm{a}_{\max } / \mathrm{a}_{\min }$ & 5.30 & 3.60 & 9.87 & 8.66 \\
\hline \multicolumn{5}{|c|}{ Indices $1 \mathrm{~min}$ after explosion } \\
\hline Measurement points: & $\mathrm{K} 2$ & K1 & K6 & $\mathrm{K} 5$ \\
\hline $\mathrm{a}_{\max } / \mathrm{a}_{\min }$ & 1.23 & 0.83 & 0.83 & 0.87 \\
\hline Measurement points: & K4 & K3 & K8 & K7 \\
\hline $\mathrm{a}_{\max } / \mathrm{a}_{\min }$ & 1.34 & 0.92 & 1.06 & 1.08 \\
\hline Location & $\begin{array}{l}\mathrm{K} 1 \text { - reduction gear, } \\
\mathrm{X} \text { axis, } \mathrm{PB} \text { (port side) }\end{array}$ & $\begin{array}{l}\text { K2 - reduction gear, } \\
\text { X axis, LB (starboard) }\end{array}$ & $\begin{array}{l}\text { K3 - reduction gear, } \\
\text { Z axis, } \mathrm{PB} \text { (port side) }\end{array}$ & $\begin{array}{l}\text { K4 - reduction gear, } \\
\text { Z axis, LB (starboard) }\end{array}$ \\
\hline Location & $\begin{array}{l}\text { K5 - intermediate shaft } \\
\text { bearing, X axis, } \\
\text { PB (port side) }\end{array}$ & $\begin{array}{c}\text { K6 - intermediate shaft } \\
\text { bearing, } X \text { axis, } \\
\text { PB (port side) }\end{array}$ & $\begin{array}{c}\text { K7 - intermediate shaft } \\
\text { bearing, } X \text { axis, } \\
\text { PB (port side) }\end{array}$ & $\begin{array}{c}\text { K8 - intermediate shaft } \\
\text { bearing, X axis, } \\
\text { PB (port side) }\end{array}$ \\
\hline
\end{tabular}

It can be observed that values of the $\mathrm{a}_{\max } / \mathrm{a}_{\min }$ ratios from before and after the explosion are close to each other; it means that the explosion impulse caused elastic deformations and next the propulsion system comes back to the initial technical state.

\section{MODELS OF EXCITATION DUE TO UNDERWATER EXPLOSION}

Analysis of dynamic impacts including impulse ones should take into account basic parameters which influence character of time-run of a given signal as well as its spectrum. The basic parameters which identify impulse impact resulting from explosion, are the following :

$\star$ form of impulse which identifies kind of impulse (Fig. 9a through 9d)

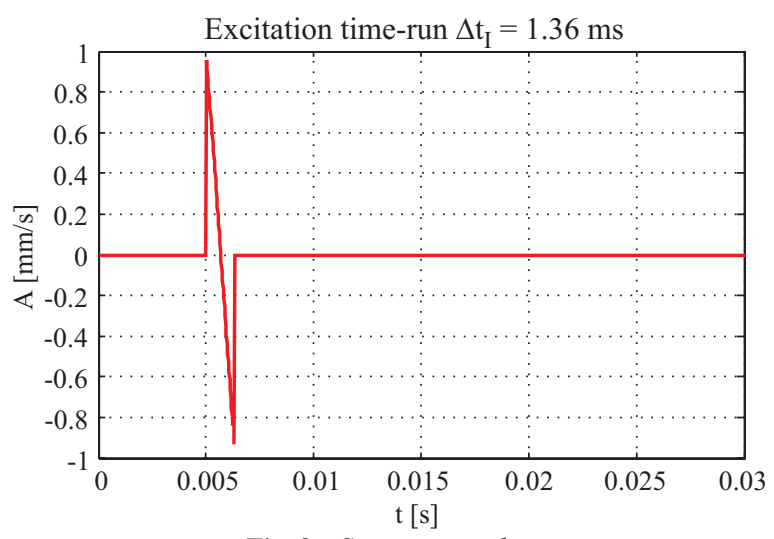

Fig. 9a. Stepwise impulse.

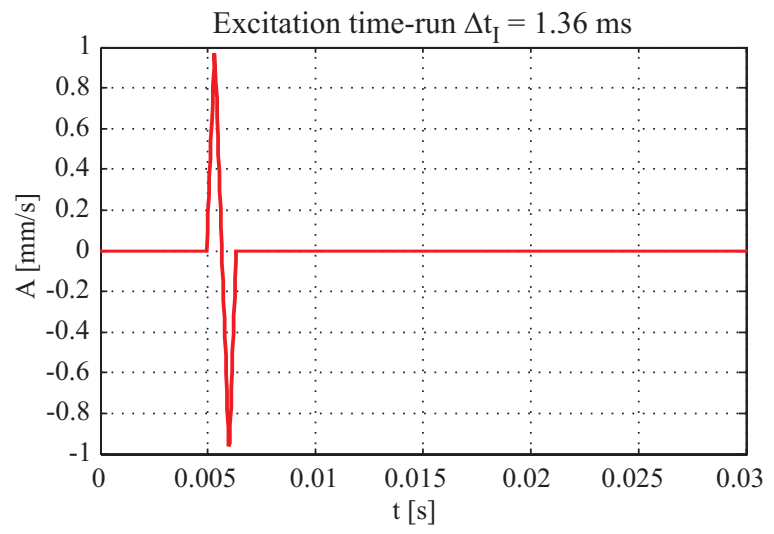

Fig. 9c. Symmetrical impulse.

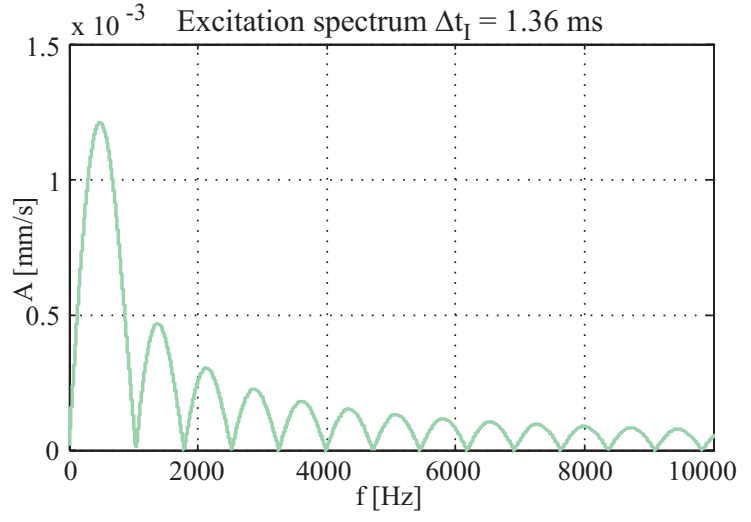

Fig. 9b. Stepwise impulse spectrum.

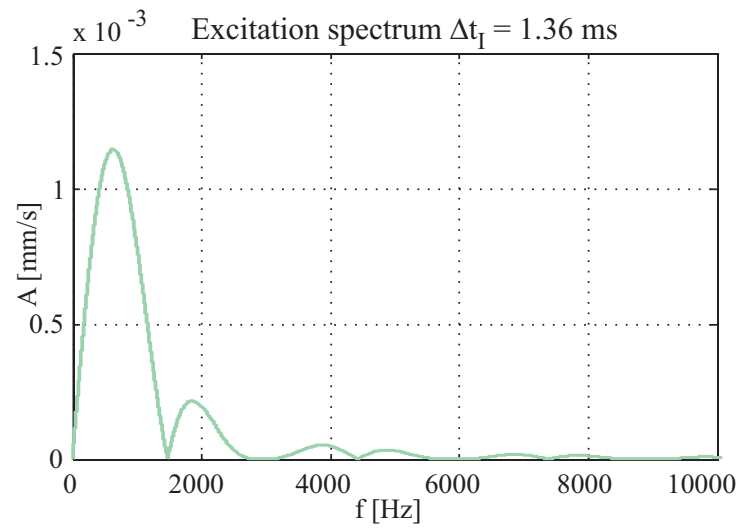

Fig. 9d. Symmetrical impulse spectrum. 
$\star$ impulse duration time $\Delta \mathrm{t}_{\mathrm{I}}$ at the ratio $\mathrm{A} / \Delta \mathrm{t}_{\mathrm{I}}$ maintained constant, which identifies explosive charge power (time of propagation of gas bubble) - Fig. 10a through 10d

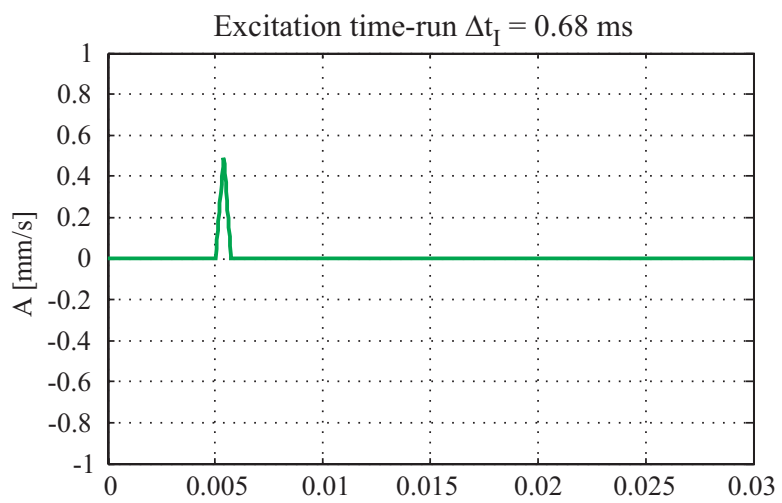

Fig. 10a. Simplified run of shock wave model in function of time $\left(\Delta t_{I}=0.68 \mathrm{~ms}\right)$.

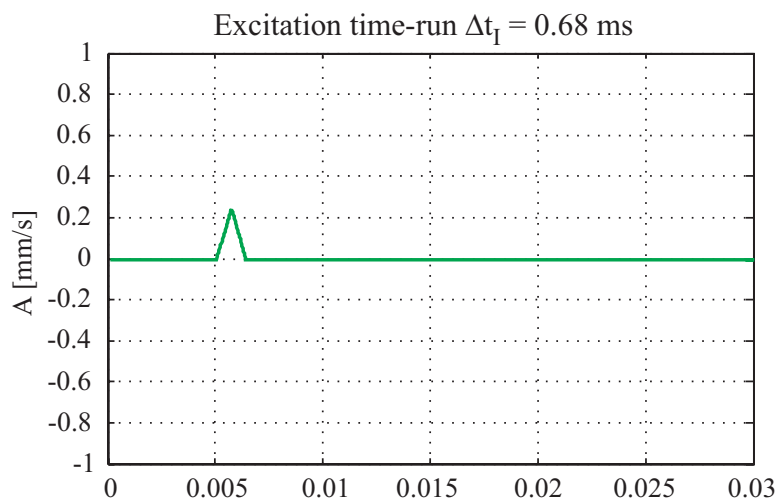

Fig. 10c. Simplified run of shock wave model in function of time $\left(\Delta t_{I}=1.36 \mathrm{~ms}\right)$.

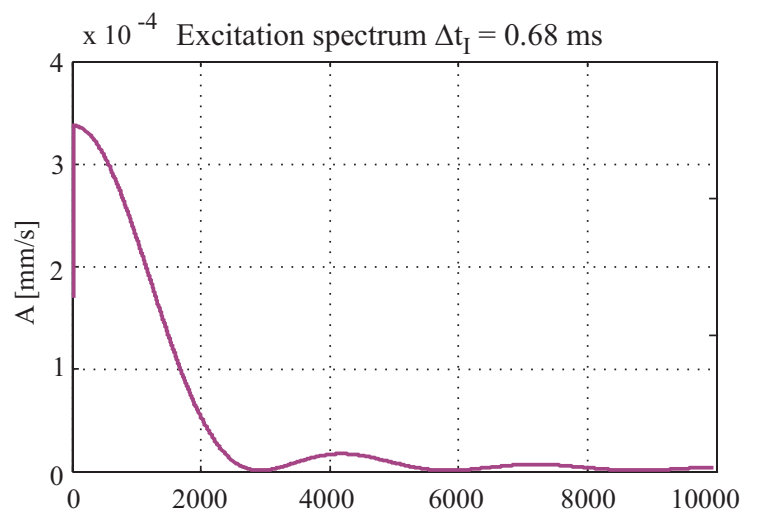

Fig. 10b. Spectrum of simplified run of shock wave model in function of time $\left(\Delta t_{I}=0.68 \mathrm{~ms}\right)$.

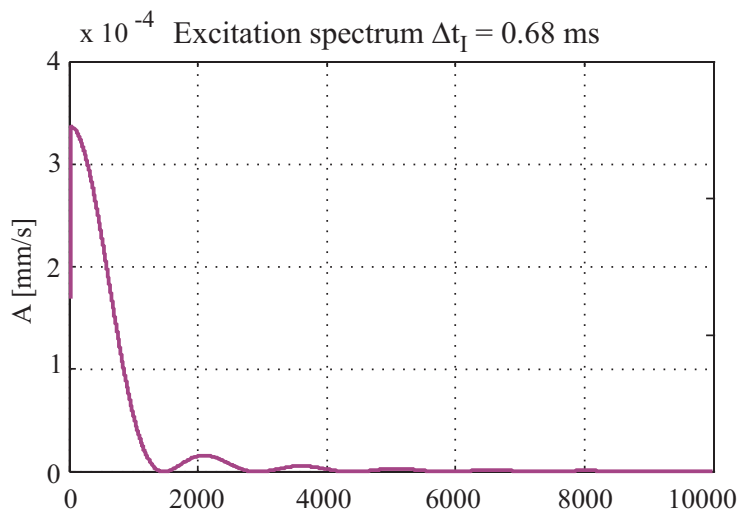

Fig. 10d. Spectrum of simplified run of shock wave model in function of time $\left(\Delta t_{I}=1.36 \mathrm{~ms}\right)$.

$\star$ influence of damping on spectrum form, which identifies distance from explosion and - simultaneously - epicentre depth (Fig. 11a through 11d)

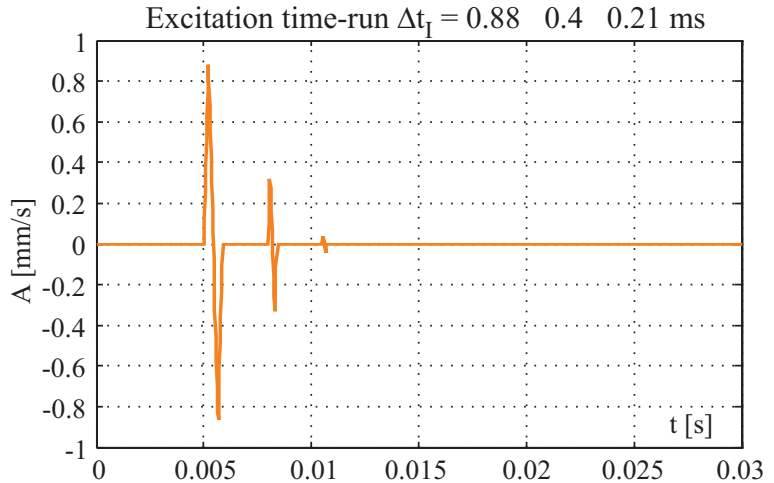

Fig. 11a. Signal which contains transformed impulses for amplitude ratios 1: $0.37: 0.05$.

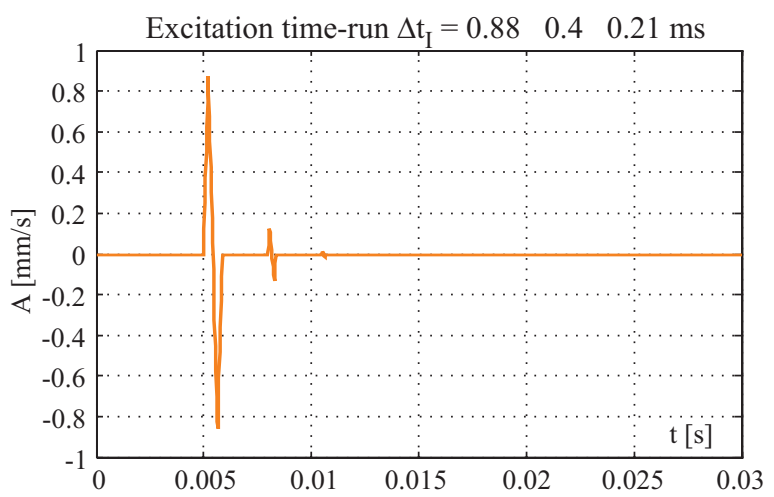

Fig. 11c. Signal which contains transformed impulses for amplitude ratios 1: $0.18: 0.02$.

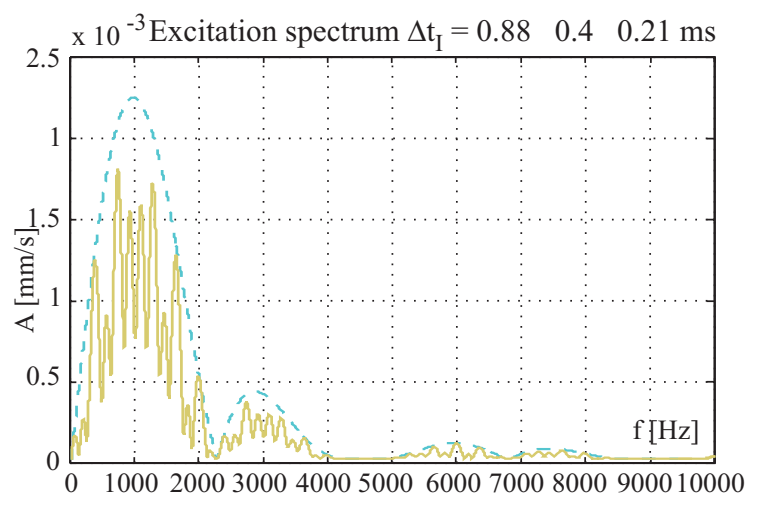

Fig. 11b. Spectrum of the signal which contains transformed impulses for amplitude ratios 1: $0.37: 0.05$.

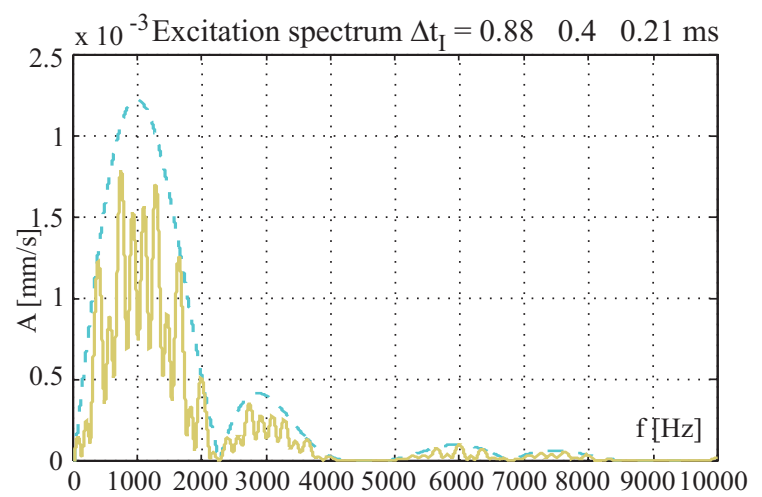

Fig. 11d. Spectrum of the signal which contains transformed impulses for amplitude ratios 1: $0.18: 0.02$. 
$\star$ number of excitation impulses, which informs on distance from explosion, combined with explosive charge mass (Fig.12a through 12d)

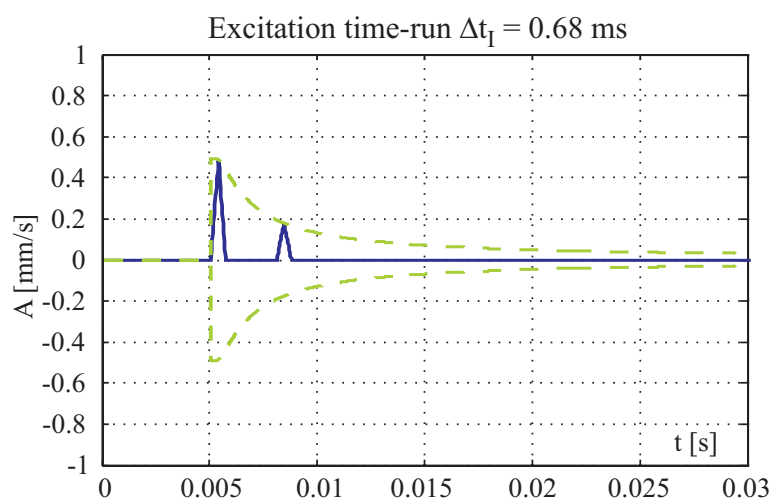

Fig. 12a. Run of shock wave model in function of time (two impulses) $t=0.68 \mathrm{~ms}$.

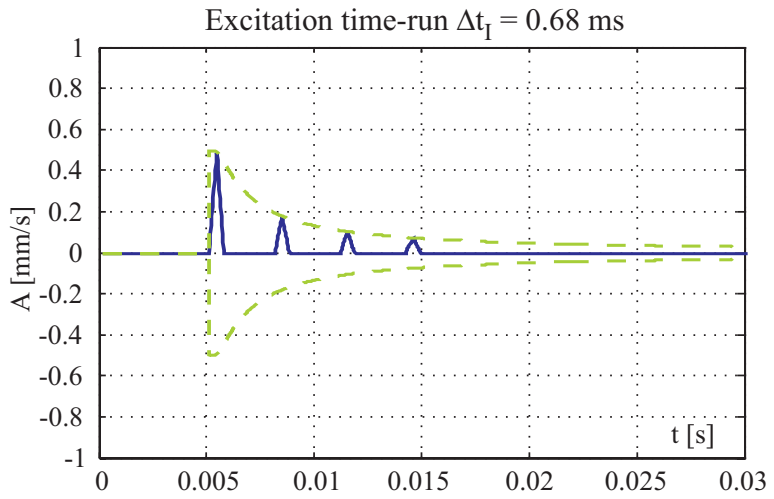

Fig.12c. Run of shock wave model in function of time (four impulses) $t=0.68 \mathrm{~ms}$.

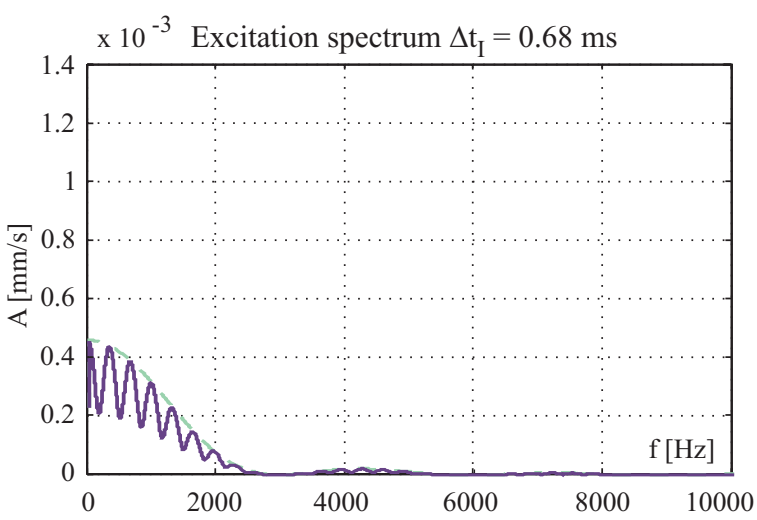

Fig. 12b. Spectrum of run of shock wave model in function of time (two impulses) $t=0.68 \mathrm{~ms}$

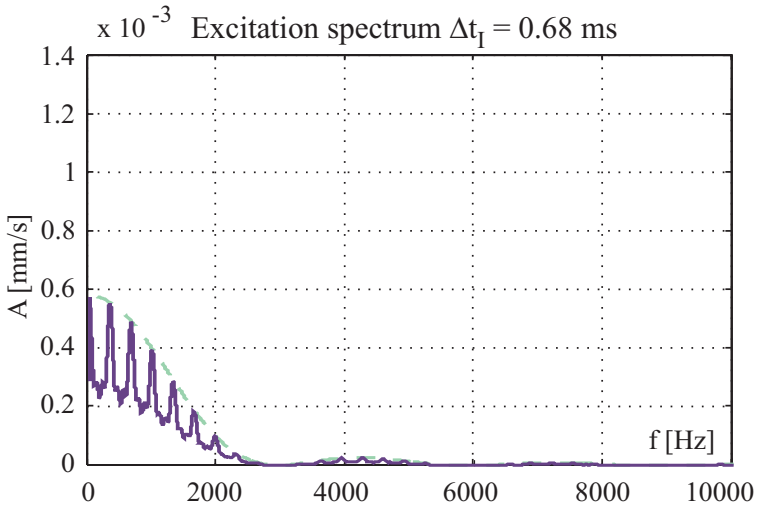

Fig. 12d. Spectrum of run of shock wave model in function of time (four impulses) $t=0.68 \mathrm{~ms}$

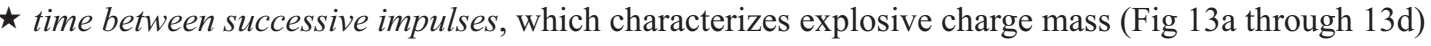

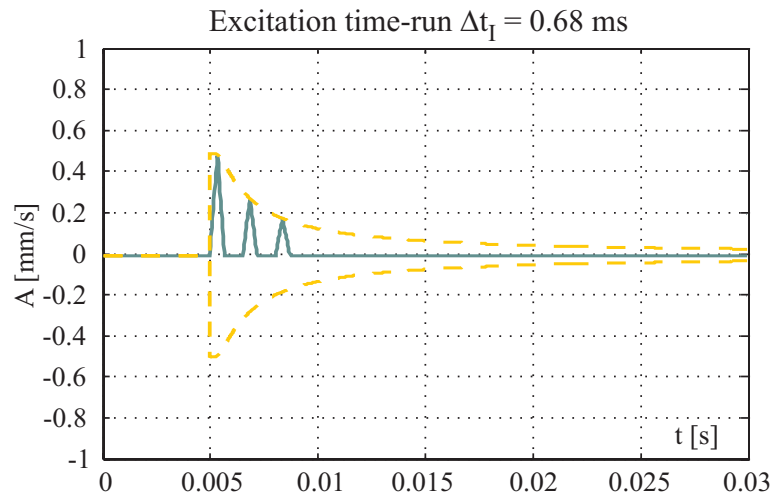

Fig. 13a. Run of shock wave model in function of time with taking into account effect of three successive gas bubbles (short time) .

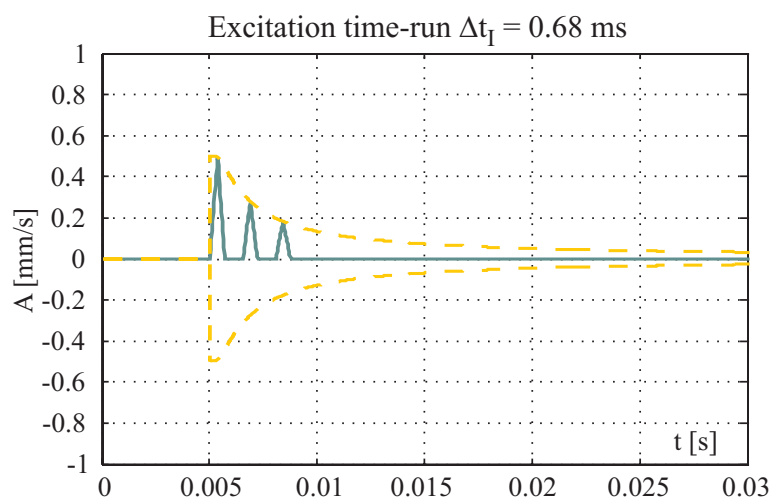

Fig. 13c. Run of shock wave model in function of time with taking into account effect of three successive gas bubbles (four times longer duration time).

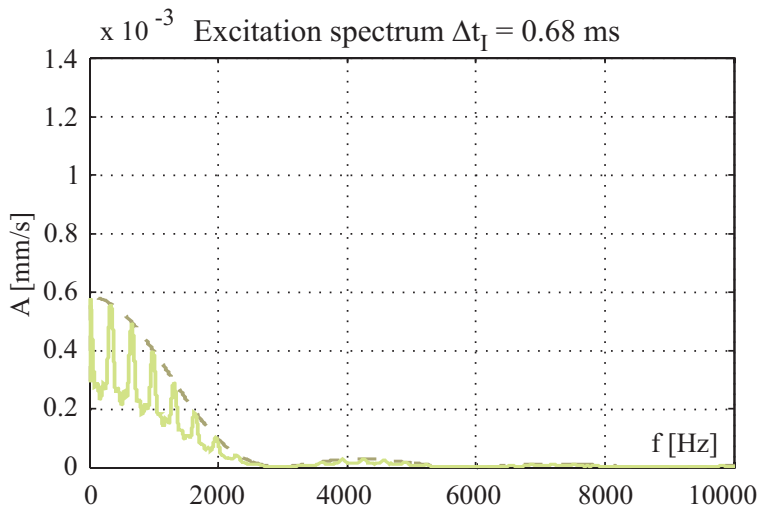

Fig. 13b. Spectrum of shock wave with three successive impacts of gas bubbles (short time)

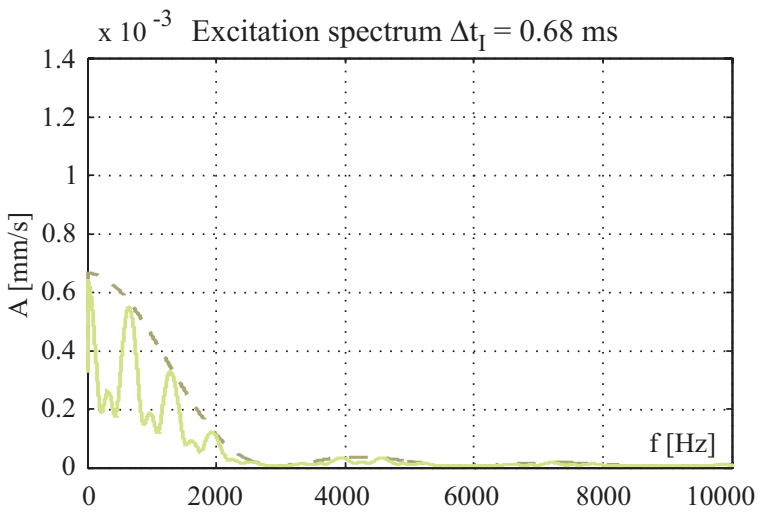

Fig. 13d. Spectrum of shock wave with three successive impacts of gas bubbles (four times longer duration time). 
The modelling of run of hydrodynamic pressure changes due to underwater explosion, in the direction normal to tangent plane at any point of hull, can make it possible to identify the quantities which characterize underwater explosion. The formulae for maximum shock wave pressure and pressure values in function of time, presented in the literature [2], do not take into consideration all the components whose values are significant for assessing degree of hazard to propeller shaft operation. As observed in Fig.4 every non-disturbed underwater explosion (by shallow water, bed structure, water non-homogeneity etc) consists of at least three shock wave impacts resulting from gas bubble pulsation. In practice the form of shock wave is limited by the following factors :

* if the distance between explosion epicentre and ship hull is small then only one time-extended impulse impact may be recorded

* if the distance between explosion epicentre and ship hull is large then impacts of the second or successive pulsations are contained within measurement background and their degree of danger to propeller shaft operation is negligible (for unlimited water area it depends on explosive charge mass and distance).

The possible recording of measured shock wave pressure and accelerations on intermediate and propeller shaft bearings enables to identify some explosion parameters hence also hazards to power transmission system. Analysing the run of underwater shock wave pressure one is able to assume its time-dependent function (Fig.14a and 14b) :

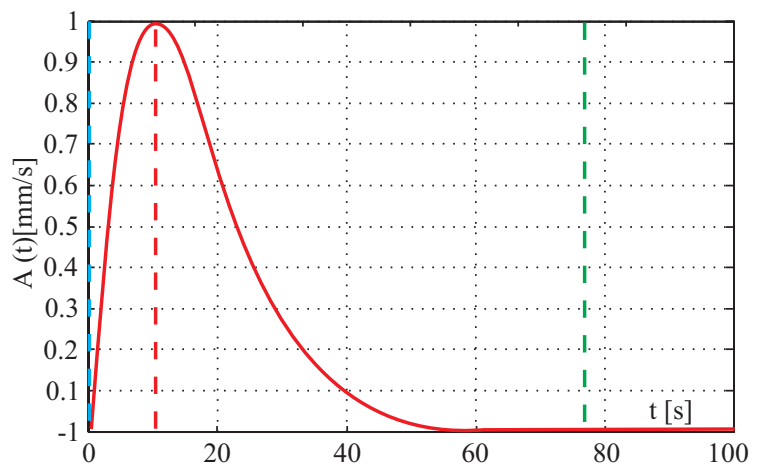

Fig. 14a. Example of the function form for $b=1.5, c=-0.15$ and $k=1$

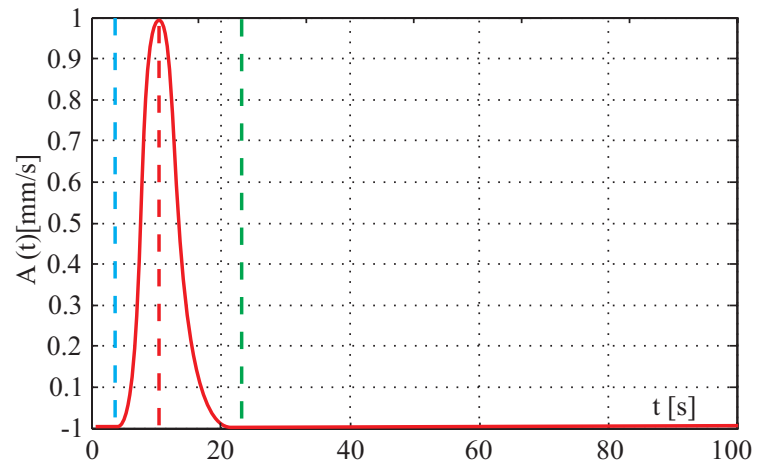

Fig. 14b. Example of the function form for $b=1.5, c=-0.15$ and $k=10$

$$
\mathrm{A}=\mathrm{at}^{\mathrm{kb}} \cdot \mathrm{e}^{\mathrm{kct}} \text { (normalized by a) }
$$

For the assumed mathematical model of the first shock wave impulse the run of vibration accelerations recorded on ship hull - for the example function given in Fig. 14a - can be presented as shown in Fig. 15a and 15b.

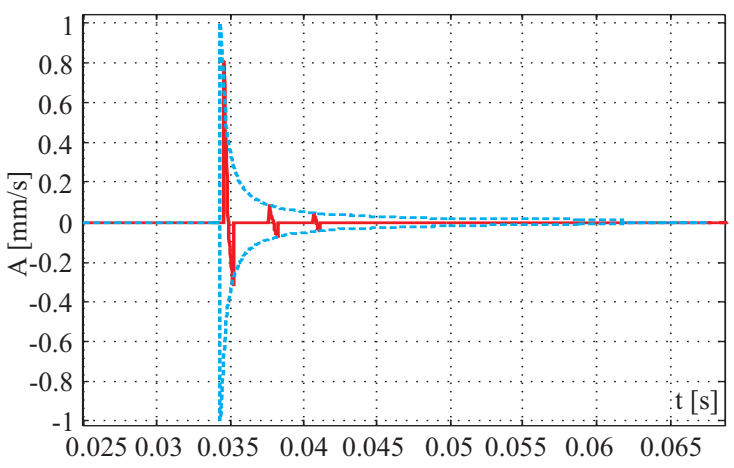

Fig. 15a. Run of the assumed vibration acceleration model

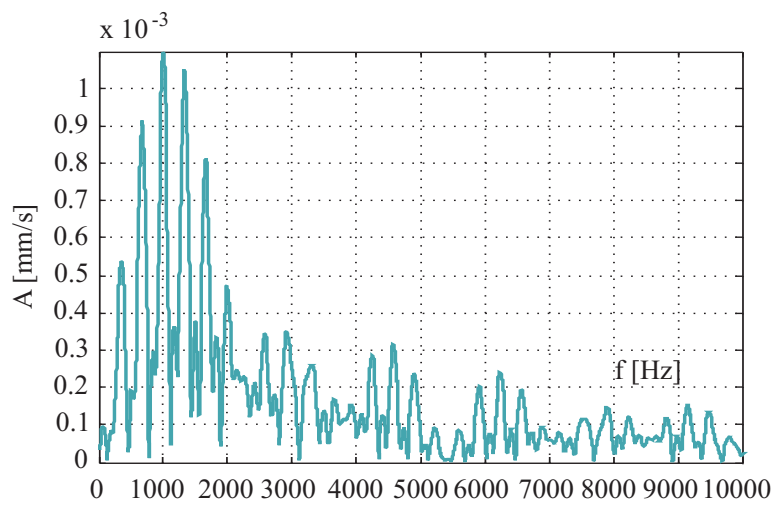

Fig. 15b. Spectrum of the assumed vibration acceleration model

\section{FINAL CONCLUSIONS}

It's common knowledge that failure frequency is the most hazardous factor in marine industry, just after aeronautics. Dynamic reactions which occur on ships in service at sea are rarely able to produce wear sufficient to cause a failure.

The possible application of an on-line monitoring system of vibration parameters of the propulsion system of mine hunter makes it possible to perform the typical technical diagnostic tests of torque transmission system and to identify possible plastic deformations of hull plating as a result of underwater explosion.

The modelling of impulse impact form and next its identification makes it possible additionally :

- to identify explosion power by using an analysis of the first vibration impulse amplitude and its duration time

- to identify distance from explosion epicentre (hence a degree of hazard) by analysing signal's damping

- to identify a kind of explosion and even characteristic features of type of used mine

- to select dynamic characteristics of a measuring system which has to comply with requirements for typical technical diagnostics and for a hazard identification system

- to identify elastic or plastic deformation of shaft line by using spectral assessment of its characteristic features from before and after underwater explosion.

The presented results of modelling related to the performed experimental test do not make it possible - due to strongly non-linear character of interactions occurring in sea environment - to assign unambiguously the modelled signal features to those of the recorded ones during the real test. 
Successive experimental tests will make it possible to verify features of the signals assumed for the analysis, to be able to build reliable models.

The wide range of stochastic dynamic loads acting on ships during its life-time makes that in the nearest future the application of on-line diagnostic techniques to ship propulsion systems, based on analysing vibration signals, will constitute an obvious tactical and technical necessity.

\section{NOMENCLATURE}

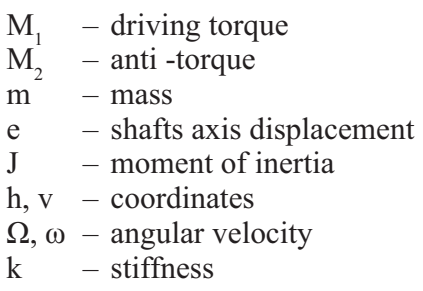

\section{BIBLIOGRAPHY}

1. Cempel Cz., Tomaszewski F. (Ed.): Diagnostics of machines. General principles. Examples of applications (in Polish), Publ. MCNEM, Radom 1992

2. Cole R. H.: Underwater Explosions. Princeton University Press, Princeton 1948

3. Cudny K., Powierża Z.: Selected problems of shock resistance of ships (in Polish) Publ. Polish Naval University, Gdynia 1987.

4. Dąbrowski Z.: Machine shafts (in Polish), State Scientific Publishing House (PWN), Warszawa 1999

5. Dietrych I, Kocańda S. Korewa W: Essentials of machine building (in Polish). Scientific Technical Publishing House (WNT), Warszawa 1974

6. Gosiewski Z., Muszyńska A.: Dynamics of rotary machines (in Polish), Publ. High School on Engineering (WSI), Koszalin 1992

7. Kaliski S.: Vibrations and waves in solids (in Polish), State Scientific Publishing House (PWN), Warszawa 1966

8. Klatka N.: Construction of passive defense devices, Part Ia and Ib (in Polish), Publ. WSMW 1985

9. Rich H. L., Effects of underwater explosions on shipboard equipment, Bureau of Ships Journal, vol. 8, no. 4, 1959

10.www.martec.com

\section{CONTACT WITH THE AUTHOR}

Andrzej Grządziela, D.Sc., Eng.

Mechanic-Electric Faculty,

Polish Naval University

Smidowicza 69

81-103 Gdynia, POLAND

e-mail : AGrza@amw.gdynia.pl

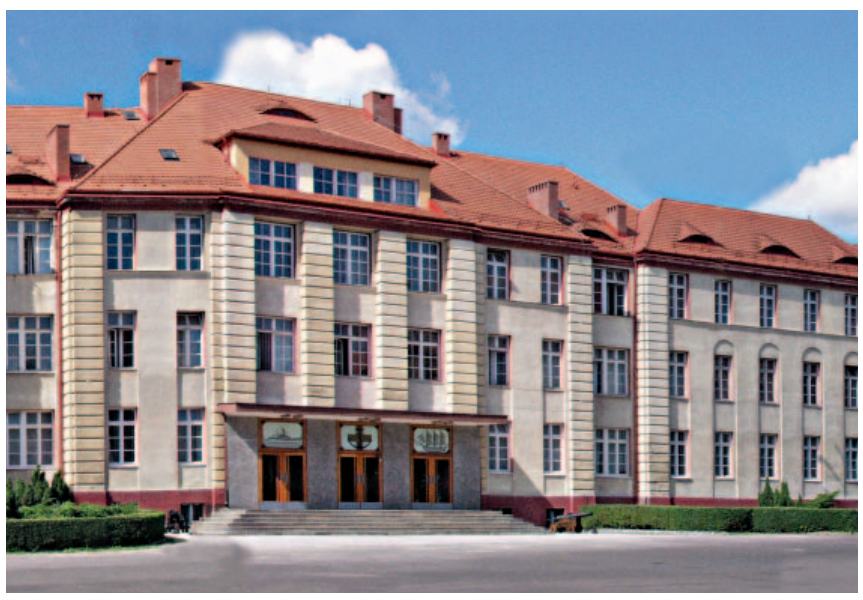

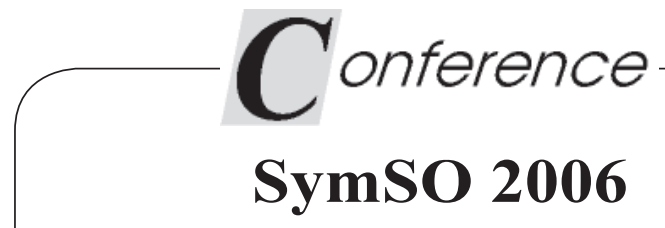

$27^{\text {th }}$ Symposium on Ship Power Plants

On 16-17 November $200627^{\text {th }}$ Symposium on Ship Power Plants was held in Szczecin. It was organized by Division of Ship Engines and Power Plants, Department of Heat Machines and Ship Power Plants, Maritime Technology Faculty, Szczecin University of Technology. Scientific patronage over the Symposium was taken by : the Marine Technology Unit of the Transport Technical Means Section, Transport Committee, Polish Academy of Sciences (PAN) and the West- Pomeranian Regional Group of the Section on Exploitation Foundations, Machine Building Committee, PAN. Arrangement of $27^{\text {th }}$ Symposium on Ship Power Plants has been included into the program of celebration of $15^{\text {th }}$ Anniversary of the Maritime Technology Faculty as well as $60^{\text {th }}$ Anniversary of Szczecin University of Technology, commencing in 2006.

Such symposia have been organized each year by similar Divisions, Departments and Institutes which educates in designing, construction and operation of ship power plants, being organizational units of : Polish Naval University of Gdynia, Gdańsk University of Technology, Gdynia Maritime University, Maritime University of Szczecin and Szczecin University of Technology.

The Symposia are aimed at forming a forum for exchange of scientific technical information and experience among scientific workers and persons employed in maritime economy enterprises and institutions in the area of the designing, manufacturing and operating of ship power plants and their devices, as well as of marine environment protection and for tightening relations between science and practice.

The organizers had honour to host - apart from representatives of the above mentioned universities - also experts in the field of industry and maritime economy. It was representatives of $\mathrm{H}$. Cegielski Works in Poznań, MAN Diesel A/S, Wartsila Polska Co Ltd, Alfa-Laval Polska Co Ltd, PBP Enamor, Bosch Rexroth Co Ltd, as well as Szczecin Nowa Shipyard Co Ltd.

During two-day proceedings 20 papers were presented in 7 sessions and another twenty in poster presentations. Themes of the papers were assigned to the following groups : Design, Diagnostics and Operation, and Environmental Protection and Safety.

The shares of the particular scientific research centres in preparation of the papers were as follows :

$\begin{array}{ll}\text { is Polish Naval University } & 8 \\ \text { it Gdańsk University of Technology } & 9 \\ \text { it Szczecin University of Technology } & 5 \\ \text { it Gdynia Maritime University } & 5 \\ \text { it Szczecin Maritime University } & 12 \\ \text { it Polish Register of Shipping } & 1\end{array}$

The next, 28th Symposium on Ship Power Plants will be organized by Gdynia Maritime University and held in November 2007. 